\title{
Do early life factors influence body mass index in adolescents?
}

M.Z. Goldani', L.S.B. Haeffner ${ }^{2}$, M. Agranonik ${ }^{1}$, M.A. Barbieri ${ }^{3}$, H. Bettiol ${ }^{3}$ and A.A.M. Silva ${ }^{4}$

\author{
'Departamento de Pediatria e Puericultura, Faculdade de Medicina, \\ Universidade Federal do Rio Grande do Sul, Porto Alegre, RS, Brasil \\ ${ }^{2}$ Centro de Ciências da Saúde, Departamento de Pediatria e Puericultura, \\ Universidade Federal de Santa Maria, Santa Maria, RS, Brasil \\ ${ }^{3}$ Departamento de Puericultura e Pediatria, Faculdade de Medicina de Ribeirão Preto, \\ Universidade de São Paulo, Ribeirão Preto, SP, Brasil \\ ${ }^{4}$ Departamento de Saúde Pública, Universidade Federal do Maranhão, \\ São Luís, MA, Brasil
}

\author{
Correspondence \\ M.Z. Goldani \\ Departamento de Pediatria e \\ Puericultura \\ Faculdade de Medicina, UFRS \\ Rua Ramiro Barcelos, 2400 \\ 90035-150 Porto Alegre, RS \\ Brasil \\ E-mail: mgoldani@hcpa.ufrgs.br \\ HC - Children \\ Research supported by FAPESP \\ (Nos. 93/0525-0 and 2000/09508-7). \\ .................................
}

Received September 18, 2006 Accepted May 11, 2007 .....................

\begin{abstract}
The association between early life factors and body mass index (BMI) in adulthood has been demonstrated in developed countries. The aim of the present study was to assess the influence of early life factors (birth weight, gestational age, maternal smoking, and social class) on BMI in young adulthood with adjustment for adult socioeconomic position. A cohort study was carried out in 1978/79 with 6827 motherchild pairs from Ribeirão Preto city, located in the most developed economic area of the country. Biological, economic and social variables and newborn anthropometric measurements were obtained shortly after delivery. In 1996, 1189 males from this cohort, $34.3 \%$ of the original male population, were submitted to anthropometric measurements and were asked about their current schooling on the occasion of army recruitment. A multiple linear regression model was applied to determine variables associated with BMI. Mean BMI was 22.7 (95\% CI $=22.5-23.0$ ). After adjustment, BMI was $1.22 \mathrm{~kg} / \mathrm{m}^{2}$ higher among infants born with high birth weight $(\geq 4000 \mathrm{~g}), 1.21 \mathrm{~kg} / \mathrm{m}^{2}$ higher among individuals of low social class at birth and $0.69 \mathrm{~kg} / \mathrm{m}^{2}$ higher among individuals whose mothers smoked during pregnancy $(\mathrm{P}<$ $0.05)$. The association between social class at birth and BMI remained statistically significant $(\mathrm{P}<0.05)$ even after adjustment for adult schooling. These findings suggest that early life social influences on BMI were more important and were not reversed by late socioeconomic position. Therefore, prevention of overweight and obesity should focus not only on changes in adult life styles but also on factors such as high birth weight.
\end{abstract}

\section{Introduction}

In developed countries, the association between early life factors (biological characteristics, social background and environment at birth and childhood) and body mass index (BMI) in adulthood has been demonstrated
Key words

- Adolescence

- Body mass index

- Perinatal factors
- Life stile in the medical literature (1-4). Studies have demonstrated that heavy newborns tend to have higher BMI in adolescence $(5,6)$. Moreover, this association also seems to be affected by the pattern of weight gain during infancy. It appears that the level of adiposity is directly related to a long-standing weight 
catch up until later in infancy in individuals who were born small for gestational age (7). Therefore, both low and high birth weight groups seem to be related to increased BMI in later life through different mechanisms.

The association between social class and BMI seems to differ between developed and developing countries. In developed countries there is an inverse association between social class and BMI, whereas in some developing countries individuals of higher social classes present a higher BMI $(8,9)$. In Brazil, national cross-sectional studies have pointed out that, over the last 30 years, BMI has been higher in most developed areas and in more privileged social strata $(10,11)$.

Among environmental factors influencing BMI in adulthood, special attention has been paid to maternal smoking, consistently related to increased fatty mass in late infancy and in adulthood (12). The probable mechanism involved appears to be independent of birth weight, affecting food preferences and changes in nutritional metabolism (13). In Brazil, however, as far we know, no study has demonstrated such association.

In the present investigation, data from a birth cohort study carried out in Ribeirão Preto, in 1978/79, were used to investigate the association between early social factors, especially birth weight, social class and maternal smoking, and BMI in late adolescence.

\section{Subjects and Methods}

A hospital-based cohort study was carried out in Ribeirão Preto, Brazil, in 1978/ 79 , involving all singleton live births. This city is located in the most developed economic area of Brazil. A total of 6827 motherchild pairs residing in the city were included. A total of 3468 male newborns were reported. Biological, economic and social variables were obtained.

Shortly after delivery, newborn measurements were obtained and the mothers were interviewed using a standardized questionnaire (14). Only $2.5 \%$ of mothers were discharged from hospital before they could be interviewed. Trained personnel supervised by the research team obtained the anthropometric data of the newborns (weight and height). Less than $1.0 \%$ of the mothers refused to be interviewed in both surveys. The hospital directors gave permission to consult the medical records after the researchers guaranteed confidentiality and the mothers gave written informed consent to be interviewed.

In 1996 and 1997, 1189 males from this cohort were located at the time of army recruitment, corresponding to $34.3 \%$ of the original male population. Anthropometric measurements were obtained. Height (in $\mathrm{cm}$ ) and weight (in $\mathrm{kg}$ ) were collected by two investigators during the medical examination at the army unit. The measurements were made twice. The precision of the weight scale was $100 \mathrm{~g}$ and the precision of the height scale was $0.5 \mathrm{~cm}$. BMI was calculated using the formula: weight/height ${ }^{2}$.

\section{Statistical analysis}

Statistical analysis included simple linear regression of each independent variable on BMI in adulthood. Later on, all variables were included in the first analysis, independent of their level of significance, and were adjusted to each other in a multiple linear regression model with BMI at 18 years of age as the dependent variable, and confounding was taken into account. Birth weight was included in the models as a categorical variable $(<2500,2500-2999,3000-3499$, $3500-3999, \geq 4000 \mathrm{~g})$. The other variables were: maternal smoking ever (yes or no), gestational age $(<37,37$ to 42 , and $>42$ weeks), and conscript's schooling and social class at birth. Conscript's schooling was divided into three groups on the basis of years spent in school: low ( $<8$ years), medium (8 to 10$)$ and high (11 or more). The latter was 
determined based on father's occupation using the International System of Classification of Occupations (ISCO-1977), modified by Bettiol et al. (14), comprising three social groups: high (non-manual occupations), medium (skilled and semiskilled manual jobs) and low (unskilled manual occupations and unemployment). Missing values were included in the model if they were greater than $5 \%$. Co-linearity and interactions among independent variables were also checked and none was detected $(\mathrm{P}<0.05)$.

\section{Results}

Mean BMI was $22.7(95 \% \mathrm{CI}=22.5$ 23.0) in this sample of 1189 males. Univariate analysis revealed significant increases in mean adolescent BMI according to birth weight, social class at birth and maternal smoking. The higher the birth weight, the higher the BMI at adolescence. Conscripts born with a high birth weight had a BMI 1.37 $\mathrm{kg} / \mathrm{m}^{2}$ higher than those weighing $<2500 \mathrm{~g}$. Individuals whose fathers at the time of their birth were engaged in unskilled jobs or were unemployed were on average $1.18 \mathrm{~kg} / \mathrm{m}^{2}$ heavier than those whose fathers had nonmanual occupations. Adolescents whose mothers smoked during pregnancy were on average $0.66 \mathrm{~kg} / \mathrm{m}^{2}$ heavier than their counterparts whose mothers did not smoke. No significant effect of conscript schooling or gestational age on BMI was observed (Table 1).

After adjustment, birth weight continued to show a positive association with BMI in late adolescence. The association between birth weight and BMI was positive and there was no suggestion of a "U"'-shaped format ( $\mathrm{P}$ value for trend $=0.001)$. Social class at birth was negatively associated with BMI. Low social class at birth corresponded to higher BMI in late adolescence. Its effect on BMI did not change after adjustment for current socioeconomic condition as measured by conscript schooling. After adjust- ment, maternal smoking remained also independently associated with BMI (Table 2).

\section{Discussion}

This study has some limitations, and therefore its results should be interpreted with caution. It was restricted to males living in an urban area, a fact that could have led to overestimation of mean BMI, which is higher in urban areas in Brazil (15). The lack of information regarding parental weight and height did not allow us to adjust for genetic influences on BMI in late adolescence. The high infant mortality rate among low birth weight newborns could have contributed to

Table 1. Body mass index according to birth weight, gestational age, social class at birth, conscript schooling, and maternal smoking during pregnancy (Ribeirão Preto birth cohort study 1978/79) ( $\mathrm{N}=1189$ adolescent males).

\begin{tabular}{|c|c|c|c|c|}
\hline Variables & $\mathrm{N}$ & Mean BMI & Coefficient & $95 \% \mathrm{Cl}$ \\
\hline \multicolumn{5}{|l|}{ Birth weight $(\mathrm{g})^{*}$} \\
\hline$<2500$ & 53 & 22.25 & 0.00 & \\
\hline 2500 to 2999 & 209 & 22.27 & 0.02 & -1.04 to 1.07 \\
\hline 3000 to 3499 & 456 & 22.57 & 0.32 & -0.68 to 1.31 \\
\hline 3500 to 3999 & 368 & 23.02 & 0.77 & -0.24 to 1.78 \\
\hline$\geq 4000$ & 103 & 23.63 & 1.37 & 0.22 to 2.53 \\
\hline \multicolumn{5}{|c|}{ Gestational age (weeks) } \\
\hline$<37$ & 59 & 22.45 & 0.00 & \\
\hline 37 to 42 & 810 & 22.84 & 0.39 & -0.54 to 1.32 \\
\hline$>42$ & 69 & 22.65 & 0.20 & -1.02 to 1.42 \\
\hline Missing & 251 & 22.50 & 0.05 & -0.94 to 1.05 \\
\hline \multicolumn{5}{|c|}{ Social class at birth* } \\
\hline High & 191 & 22.21 & 0.00 & \\
\hline Intermediate & 722 & 22.70 & 0.48 & -0.07 to 1.04 \\
\hline Low & 209 & 23.40 & 1.18 & 0.50 to 1.87 \\
\hline Missing & 67 & 22.57 & 0.36 & -0.61 to 1.33 \\
\hline \multicolumn{5}{|c|}{ Conscript schooling } \\
\hline Low & 254 & 22.62 & 0.00 & \\
\hline Intermediate & 496 & 22.83 & 0.21 & -0.32 to 0.74 \\
\hline High & 439 & 22.69 & 0.07 & -0.47 to 0.62 \\
\hline \multicolumn{5}{|c|}{ Maternal smoking during pregnancy* } \\
\hline No & 270 & 23.23 & 0.00 & \\
\hline Yes & 880 & 22.57 & 0.66 & 0.18 to 1.14 \\
\hline Missing & 39 & 23.18 & 0.61 & -0.51 to 1.73 \\
\hline
\end{tabular}

${ }^{*} \mathrm{P}<0.05$ for the dependent variable body mass index (BMI) and independent variables birth weight, social class at birth and maternal smoking. Simple linear regression models were used. 
an underestimate of mean BMI among individuals with a low birth weight. Finally, poor health and social disadvantages could have been reasons for not enlisting in the army, possibly decreasing the estimate of mean BMI among less privileged social strata in late adolescence (16).

Even considering these important points, the study was able to demonstrate associations between birth weight, maternal smoking during pregnancy and childhood social class with BMI 18 years later. It was also able to explore the effect of early and late

Table 2. Multiple linear regression of body mass index adjusted for social class, gestational age, social class at birth, conscript schooling, and maternal smoking during pregnancy (Ribeirão Preto birth cohort study 1978/79) ( $N=1189$ adolescent males).

\begin{tabular}{|c|c|c|}
\hline Variables & B & $95 \% \mathrm{Cl}$ \\
\hline \multicolumn{3}{|l|}{ Birth weight $(g)^{*}$} \\
\hline$<2500$ & 0.00 & \\
\hline 2500 to 2999 & 0.12 & -1.21 to 0.97 \\
\hline 3000 to 3499 & 0.14 & -0.91 to 1.20 \\
\hline 3500 to 3999 & 0.66 & 0.41 to 1.74 \\
\hline$\geq 4000$ & 1.22 & 0.01 to 2.45 \\
\hline \multicolumn{3}{|c|}{ Gestational age (weeks) } \\
\hline$<37$ & 0.00 & \\
\hline 37 to 42 & 0.07 & -0.91 to 1.05 \\
\hline$>42$ & -0.19 & -1.45 to 1.07 \\
\hline Missing & -0.26 & -1.31 to 0.80 \\
\hline \multicolumn{3}{|c|}{ Social class at birth* } \\
\hline High & 0.00 & \\
\hline Intermediate & 0.49 & -0.08 to 1.05 \\
\hline Low & 1.21 & 0.49 to 1.93 \\
\hline Missing & -0.46 & -1.85 to 0.92 \\
\hline \multicolumn{3}{|c|}{ Conscript schooling } \\
\hline Low & 0.00 & \\
\hline Intermediate & 0.05 & -0.49 to 0.59 \\
\hline High & -0.31 & -0.88 to 0.26 \\
\hline \multicolumn{3}{|c|}{ Maternal smoking during pregnancy* } \\
\hline No & 0.00 & \\
\hline Yes & 0.69 & 0.21 to 1.17 \\
\hline Missing & 1.90 & 0.16 to 3.63 \\
\hline
\end{tabular}

${ }^{*} \mathrm{P}<0.05$ for the dependent variable body mass index (BMI) and independent variables birth weight, social class at birth and maternal smoking. All variables were included in the first analysis, independent of their level of significance. social factors by using social indicators at two points of an individual's lifetime, i.e., at birth and during late adolescence.

Studies conducted in Brazil have reported that individuals from high social strata have a higher BMI during adulthood (8), whereas in developed countries individuals of low social classes have a higher BMI $(3,17,18)$. In our study low social class in childhood but not in adulthood was associated with higher BMI in adolescence. In addition, in some developed areas a bimodal distribution of BMI has been observed, particularly among women, i.e., those from low and high social classes present higher BMI than those from middle-class groups (19). Unfortunately, in the present study it was not possible to analyze this pattern due to the gender restriction. The mechanisms by which social factors influence BMI are complex. Some variables have been able to explain the higher $\mathrm{BMI}$ in higher social groups in developing countries such as eating behavior, sedentary life style and hours of watching television (20).

Our data suggest that early life social class is more important than late socioeconomic position for predicting BMI in adolescence. Current conscript schooling was not associated with BMI before or after adjustment for early life factors and the association with social class at birth remained statistically significant even after adjustment for current conscript schooling. Therefore, the present findings suggest that early life social influences on BMI were not reverted by late socioeconomic position.

Despite a small size effect, the positive association between birth weight and BMI supports the hypothesis that birth weight can partially mediate body size during adulthood $(21,22)$. Higher BMI among individuals born with a high birth weight has been related to an increase in fat-free mass in adulthood rather than a rise in adipose tissue $(5,6)$. However, higher BMI among individuals born with low birth weight, particu- 
larly among those born with intra-uterine growth restriction, has been associated with a predominant increase in fat mass in adulthood. It seems that prolonged catch-up in weight in individuals born small for gestational age can lead to a significant increase in adiposity in adulthood due to metabolic changes related to insulin, leptin or adiponectin resistance $(23,24)$. In our study, BMI was not increased among adolescents with low birth weight. Unfortunately, we do not have data on catch-up growth in the first years of life to test the hypothesis that low birth weight individuals who experience catch-up growth have a higher BMI in later life. If high BMI had been present only among low birth weight individuals who catch up early in growth we could not have identified this phenomenon. Although it seems unlikely, selection bias caused by higher rates of infant mortality among the low birth weight group could also have contributed to an underestimate of the possible effect of low birth weight on late BMI. Had an association between low birth weight and high BMI been present, it would have been a matter of concern because of the steady reduction in infant mortality in Brazil during the last 20 years leading to increasing survival of low birth weight babies $(25,26)$.

An independent association between maternal smoking and overweight in later life has been established in previous studies
$(12,13,27)$ and our findings corroborated the independent influence of maternal smoking on BMI in adolescence. A possible underlying mechanism involves permanent changes in hypothalamic regulation of food intake leading to changes in diet preference (28). Unfortunately, due to lack of information, in our study it was not possible to control for the influence of nutrient intake or diet preference on BMI. Because smoking mothers breast feed their babies for shorter periods of time (29) and usually feed them later on a diet rich in saturated fatty acids and cholesterol (30), confounding by these factors may also be a possible explanation for this finding. Thus, the significant influence, despite the small size effect, of maternal smoking on BMI should be considered with caution.

The findings that low social class at birth, high birth weight, and maternal smoking during pregnancy are associated with higher BMI during the teenage years indicate a complex influence of early life events on BMI and highlight the importance of early life factors in the genesis of overweight and adiposity. Therefore, prevention of overweight and obesity should focus not only on changes in adult life styles but also on early interventions supporting nutritional and behavioral changes, such as smoking cessation during pregnancy, as well as broad improvements of environmental and social conditions during prenatal and early life years.

\section{References}

1. Parsons TJ, Power C, Logan S, Summerbell CD. Childhood predictors of adult obesity: a systematic review. Int J Obes Relat Metab Disord 1999; 23 (Suppl 8): S1-S107.

2. Overpeck MD, Hediger ML, Ruan WJ, Davis WW, Maurer KR, Troendle JF, et al. Stature, weight, and body mass among young US children born at term with appropriate birth weights. J Pediatr 2000; 137: 205-213.

3. Rasmussen F, Johansson M. The relation of weight, length and ponderal index at birth to body mass index and overweight among 18-year-old males in Sweden. Eur J Epidemiol 1998; 14: 373-380.

4. Gnavi R, Spagnoli TD, Galotto C, Pugliese E, Carta A, Cesari L.
Socioeconomic status, overweight and obesity in prepuberal children: a study in an area of Northern Italy. Eur J Epidemiol 2000; 16: 797-803.

5. Monteiro PO, Victora CG, Barros FC, Monteiro LM. Birth size, early childhood growth, and adolescent obesity in a Brazilian birth cohort. Int J Obes Relat Metab Disord 2003; 27: 1274-1282.

6. Drachler ML, Andersson MC, Leite JC, Marshall T, Aerts DR, Freitas $\mathrm{PF}$, et al. Social inequalities and other determinants of height in children: a multi-level analysis. Cad Saúde Pública 2003; 19: 18151825.

7. Ezzahir N, Alberti C, Deghmoun S, Zaccaria I, Czernichow P, Levy- 
Marchal C, et al. Time course of catch-up in adiposity influences adult anthropometry in individuals who were born small for gestational age. Pediatr Res 2005; 58: 243-247.

8. da Veiga GV, da Cunha AS, Sichieri R. Trends in overweight among adolescents living in the poorest and richest regions of Brazil. Am J Public Health 2004; 94: 1544-1548.

9. Ball K, Crawford D. Socioeconomic status and weight change in adults: a review. Soc Sci Med 2005; 60: 1987-2010.

10. Sichieri R, Coitinho DC, Leao MM, Recine E, Everhart JE. High temporal, geographic, and income variation in body mass index among adults in Brazil. Am J Public Health 1994; 84: 793-798.

11. Monteiro CA, D'A Benicio MH, Conde WL, Popkin BM. Shifting obesity trends in Brazil. Eur J Clin Nutr 2000; 54: 342-346.

12. Oken E, Huh SY, Taveras EM, Rich-Edwards JW, Gillman MW. Associations of maternal prenatal smoking with child adiposity and blood pressure. Obes Res 2005; 13: 2021-2028.

13. Wideroe M, Vik T, Jacobsen G, Bakketeig LS. Does maternal smoking during pregnancy cause childhood overweight? Paediatr Perinat Epidemiol 2003; 17: 171-179.

14. Bettiol H, Barbieri MA, Gomes UA, Andrea M, Goldani MZ, Ribeiro ER. Perinatal health: methodology and characteristics of the studied population. Rev Saúde Pública 1998; 32: 18-28.

15. Popkin BM. The nutrition transition in low-income countries: an emerging crisis. Nutr Rev 1994; 52: 285-298.

16. Haeffner LS, Barbieri MA, Rona RJ, Bettiol H, Silva AA. The relative strength of weight and length at birth in contrast to social factors as determinants of height at 18 years in Brazil. Ann Hum Biol 2002; 29: 627-640.

17. Tabone MD, Vincelet $C$. Socioeconomic status and child health: the experience of the Paris Child Health Checkup Center. Arch Pediatr 2000; 7: 1274-1283.

18. Martinez JA, Kearney JM, Kafatos A, Paquet S, Martinez-Gonzalez MA. Variables independently associated with self-reported obesity in the European Union. Public Health Nutr 1999; 2: 125-133.

19. Monteiro CA, Conde WL, Popkin BM. Is obesity replacing or adding to undernutrition? Evidence from different social classes in Brazil.
Public Health Nutr 2002; 5: 105-112.

20. Fonseca VM, Sichieri R, da Veiga GV. Factors associated with obesity among adolescents. Rev Saúde Pública 1998; 32: 541-549.

21. Tuvemo T, Cnattingius S, Jonsson B. Prediction of male adult stature using anthropometric data at birth: a nationwide populationbased study. Pediatr Res 1999; 46: 491-495.

22. Sorensen HT, Sabroe S, Rothman KJ, Gillman M, Fischer P, Sorensen TI. Relation between weight and length at birth and body mass index in young adulthood: cohort study. BMJ 1997; 315: 1137.

23. Iniguez G, Soto N, Avila A, Salazar T, Ong K, Dunger D, et al. Adiponectin levels in the first two years of life in a prospective cohort: relations with weight gain, leptin levels and insulin sensitivity. J Clin Endocrinol Metab 2004; 89: 5500-5503.

24. Wells JC, Hallal PC, Wright A, Singhal A, Victora CG. Fetal, infant and childhood growth: relationships with body composition in Brazilian boys aged 9 years. Int J Obes 2005; 29: 1192-1198.

25. Silva AA, Barbieri MA, Gomes UA, Bettiol H. Trends in low birth weight: a comparison of two birth cohorts separated by a 15-year interval in Ribeirão Preto, Brazil. Bull World Health Organ 1998; 76: 73-84.

26. De Farias Aragao V, Barbieri MA, Moura Da Silva AA, Bettiol H, Ribeiro VS. Risk factors for intrauterine growth restriction: a comparison between two Brazilian cities. Pediatr Res 2005; 57: 674-679.

27. Von Kries R, Toschke AM, Koletzko B, Slikker W Jr. Maternal smoking during pregnancy and childhood obesity. Am J Epidemiol 2002; 156: 954-961.

28. Kane JK, Parker SL, Matta SG, Fu Y, Sharp BM, Li MD. Nicotine upregulates expression of orexin and its receptors in rat brain. Endocrinology 2000; 141: 3623-3629.

29. Von Kries R, Koletzko B, Sauerwald T, von Mutius E, Barnert D, Grunert V, et al. Breast feeding and obesity: cross sectional study. BMJ 1999; 319: 147-150.

30. Dallongeville J, Marecaux N, Fruchart JC, Amouyel P. Cigarette smoking is associated with unhealthy patterns of nutrient intake: a meta-analysis. J Nutr 1998; 128: 1450-1457. 